\title{
Implementation of low-rise construction projects as factor of improving level and quality of life in depressed territories
}

\author{
Natalya Gusakova ${ }^{1 *}$, Nikolay Minaev ${ }^{2}$, and Alexander Gusakov ${ }^{1}$ \\ ${ }^{1}$ Tomsk State University of architecture and building, 2 area of Salt, Tomsk 634003 Russian \\ Federation \\ ${ }^{2}$ Tomsk State Pedagogical University, 60 street Kievskaya, Tomsk 634061 Russian Federation
}

\begin{abstract}
The conducted research was devoted to the development and validation of criteria for low-rise housing construction in small towns and rural areas remote from major cities. The purpose of the research is to develop fundamental criteria that allow achieving a synergistic effect based on integrated development of a territory, together with improvement of standard of living and creation of comfortable conditions for the population. This research can be applied in design of programs for development of construction industry, including low-rise construction. Scientific merit of the article lies in the fact that the developed criteria make it possible to identify the main features of efficient low-rise housing construction: comfort, safety, energy efficiency, modernity of engineering equipment. These features are able to ensure construction of such energy-efficient lowrise comfortable and affordable housing, which will contribute to sustainable development of a region and make small towns and villages attractive for young professionals and young families.
\end{abstract}

\section{Introduction}

Now the Russian Federation is actively developing regulatory documentation on strategic territorial planning with implementation of priority national projects in the main problem areas of life - housing, health, education and agriculture. Relevance and importance of such projects stem from modern conditions of economic and social life, moreover, improvement of population's level and quality of life is becoming the main development trajectory of all developed countries [1].

One of the main conditions for increase in population's living standards is housing. The construction complex over the past decade has been characterized by a fairly high rate of low-rise construction in the outskirts of cities and suburban areas, without much emphasis on quality, compliance with regulatory requirements, energy efficiency and safety. Selection of housing type is of great significance in the course of achieving a purpose of comprehensive development of small towns and villages. This applies not only to private housing

*Corresponding author: gusakovanata@mail.ru 
construction but also to construction of low-rise residential premises. First, this will reduce construction costs and, secondly, it will shorten the construction period. (Fig. 1).

Implementation of market reforms failed to take into account regional aspects of development, efficiency of using regional resources and ignored the need to develop a unified social and economic environment of the country, ensuring control over vast territories of the Russian Federation. Meanwhile, a significant number of Russian citizens (37.3 million people) live in villages and small towns.

Consequences of underestimating the role of such settlements are obvious: deterioration of the economic basis of small towns and districts; desolation of certain territories due to physical extinction of populations of small cities and moving of the most employable population from small urban localities to large cities and megacities; destruction of engineering and technical systems and industrial and social infrastructure, abandonment, and downfall of the Russian province [2].

As of 2019, there were 1116 cities, 1239 urban-type settlements, and 154017 rural localities in the Russian Federation according to the Russian National Classification of Municipal Territories. In comparison with 1989, the number of villages and settlements had decreased by 9.2 thousand, and the number of rural settlements without residents had gone up from 9.4 thousand in 1989 to 19.4 thousand in 2010 .

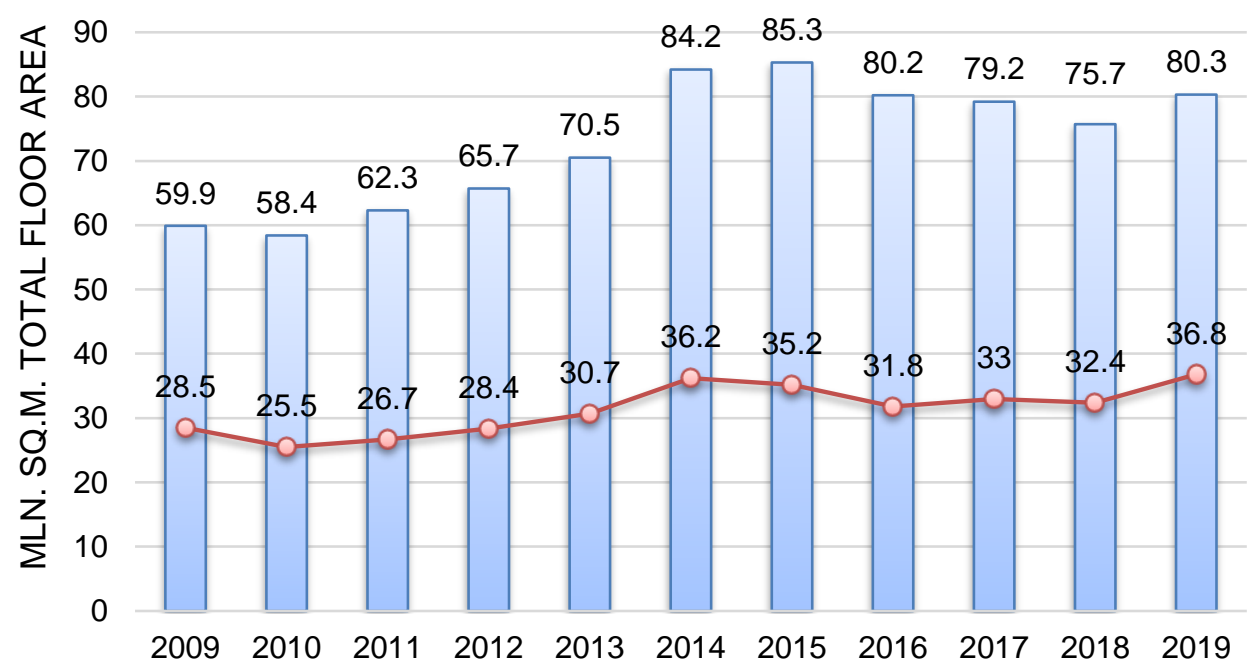

$\square$ Total amount of built housing in RF $\quad-0$ - Total amount of detached housing

Fig. 1. Dynamics of residential buildings' commissioning in the Russian Federation, mln. $\mathrm{m}^{2}$

\section{Theoretical part}

Today, low-rise construction in Russia is one of important reserves for development of the construction complex, which is bale to increase the pace of construction during crisis. However, not only state assistance is required here, but also clear requirements of the legislation. Foreign experience of many countries shows relevance of requirements for ensuring energy efficiency of buildings [3, 4]. Works devoted to improving living standards do not take into account complex effect in the construction of buildings.

Analysis of low-rise construction $[5,6]$ shows that in order to solve socio-economic issues of provision affordable and comfortable housing, remote from major cities for a special 
category of citizens, low-rise residential construction should represent the following complex of interrelated requirements and conditions:

- possess uniform requirements for space-planning and structural solutions (technical calculation is to depend on territory and climate conditions, and utilize local construction materials);

- utilize modern engineering equipment that meets requirements of energy and resource saving, and can increase energy efficiency of a building throughout its life cycle (heat supply, water supply);

- take into account provision of private-owned land plot which is an integral factor of living comfort;

- provide more favorable environmental conditions (compared to urban agglomerations, megacities);

- be based on economic efficiency of such housing both at the construction stage and during operation of facility.

\section{Materials and methods}

According to the above, criteria to achieve a synergistic effect based on integrated development of low-rise construction in remote areas were defined [7]. These criteria are:

1. Security.

2. Comfort of living.

3. Energy efficiency.

4. Economic efficiency.

One of the reasons for an unfavorable situation in complex development of small towns and villages is low level of comfort in rural areas, lack of housing that would meet requirements of comfort, safety, energy efficiency, and be equipped with modern engineering equipment. Construction of low-rise housing is usually carried out on its own without taking into account modern requirements and engineering equipment. Moreover, pace of provision of comfortable housing for young families and professionals who are officially recognized as being in need of better housing conditions is not satisfactory and requires a comprehensive approach to this problem [8].

The first attempt to create favorable living conditions in Russian settlements was made in 1996. Decree of the Government of the Russian Federation No. 762 as of June 28, 1996 approved the Federal comprehensive program for development of small and medium-sized towns of the Russian Federation in the context of the economic reform. The main goal of the program was to recover from the economic crisis and create conditions for sustainable selfdevelopment of small and medium-sized towns during the period of formation of market relations [9].

Currently, on the territory of the Russian Federation there are programs aimed at developing standards of quality of life in rural areas:

1. State Program of the Russian Federation for Integrated Rural Development for the period of $2020-2025$. One of the goals of the program is to create conditions for provision of affordable and comfortable housing for the rural population [10].

2. In 2012, the Government of the Russian Federation developed the Zemsky Doctor State Support Program, which aimed at attracting young professionals in medical sphere to small towns and villages. This program provides young professionals with a payment of up to 2 million rubles to purchase housing [11].

3. The Zemsky Teacher State Support Program. The project that will help attract young teachers to the village at the expense of an appointment allowance was developed in 2019. Decree No. 1430 as of November 9, 2019 approved the Rules for granting and distributing subsidies to federal subjects for making one-time compensation payments in the amount of 
up to 2 million rubles to teachers [12]. It will operate by analogy with the existing Zemsky Doctor program, which allowed attracting young qualified medical workers.

Having analyzed the existing programs of state support, it can be pointed out that there is no control over expenditure of the subsidized money. It is assumed that persons receiving subsidies will have to spend the money on purchase of housing solely because their contract stipulates 5 years of working in rural area. At the same time, there are no housing programs for young professionals who need to improve their housing conditions. According to statistics, the shortage of young professionals is more than 30 thousand people [13].

In the authors' opinion, the most efficient and realistic strategy from the point of view of financial provision is instead of offering citizens cash payments for the purchase of housing, which is virtually none in rural territories, but constructing comfortable housing that meets requirements of safety, energy efficiency, which will improve the level and quality of life of the population, increase achievement of target indicators and indicators of sustainable development of rural areas, as well as rational use of budgetary funds. What is more, utilization of modern energy-efficient equipment will significantly reduce cost of utilities and improve comfort of living for citizens [14].

\section{Results}

As a result of the research, a comprehensive approach to developed system of criteria was built. It allows solving the problem of creating a modern type of low-rise building that meets criteria of safety, comfort of living, energy efficiency, and efficiency of capital investment, based on a comprehensive analysis of issues associated with social, economic, and climatic features of regional development.

Currently, there is a significant need for economy-class housing for young professionals. The structure of low-rise buildings should be dominated by pre-fabricated, low-cost and cheap in operation structures. The next step in structuring the given methodology will be development of methods, which can evaluate efficiency of capital investment into low-rise construction over the full life cycle of a building under selected conditions, as well as the strategy of provision of young professionals with such housing.

Construction of energy-efficient, low-cost housing within the framework of state support programs will allow purchasing comfortable housing, reducing the cost of utilities, thereby increasing the level and quality of life by improving housing conditions of citizens living in remote areas, including young families and young professionals in the field of medicine, education and culture. Provision of such type of housing should be carried out at the expense of the federal and local budgets of the subjects of the Russian Federation and include mechanisms of maternity capital and mortgage housing credit when purchasing housing, increasing volume of housing construction in rural areas by means of stimulating investment activity in the housing sector. It is also necessary to take into account large-scale results of development of comprehensive low-rise construction activities in small towns and rural areas, which is primarily construction of social facilities, such as schools, kindergartens, clinics, that will increase the number of jobs in this area. It is also an opportunity to increase investment attractiveness, create new jobs, increase tax base of municipal budgets and ensure high level of quality of life and, as a result, overall growth of the rural economy.

\section{References}

1. A.T. Aidarbekova, An integrated approach to the development of rural areas, Innovation science. 6-1, 17-19 (2016) 
2. S.A. Gurfova, D.A. Ivazova, Sustainable development of rural areas, Actual problems of the modern economy, 3, 112-116 (2014)

3. A. Alberini, A. Bigano, How effective are energy-efficiency incentive programs? Evidence from Italian homeowners. Energy Econ. 52, 76-85 (2015)

4. E. Weizsäcker, K. C. Hargroves, and M. H. Smit, Factor Five. The Formula for Sustainable Growth: a Report to the Roman Club (Ast-Press Book, Moscow, 2013).

5. V.S. Kazeikin, S.A. Baronin, A.G. Chernikh, A.N. Androov, Problem aspects of development of low-rise construction in Russia: Monograph, (Edited by academician V.S. Kazeikin and prof. S.A. Baronin. Moscow 2011) [in Russian]

6. A. N. Asaul, I. N. Kazakov, N. I. Pasiada, and I. V. Denisova, Theory and Practice of Low-rise Residential Housing (Gumanistika Publishing, Petersburg, 2005) [in Russian]

7. K.E. Filyushina, N.N. Minaev, N.V. Gusakova, O.I. Dobrynina, Y.A. Zharova, Y.A. Merkulyeva, A.S. Runkova, Justification of contemporary organization model of residential low-rise, Bulletin of Tomsk State University of Architecture and Building, 3(56), 166-178 (2016)

8. S.G. Sheina, Development of Optimized Model for Selection of Energy Efficient Solutions in Low-rise Construction (Rostov State University of Civil Engineering, Rostov-on-Don, 2013).

9. Resolution of the Government of the Russian Federation N 762 from 28.06.1996 "On approval of the Federal comprehensive program for the development of small and medium-sized cities of the Russian Federation in the context of economic reform" (no longer valid) - 25.04.2020 (in Russian).

10. On approval of the state program of the Russian Federation "Integrated Development of Rural Territories" and on amendments to some acts of the Government of the Russian Federation (as amended on March 31, 2020). Accessed: http://docs.cntd.ru/ document / 554801411.

11. On approval of the state program of the Russian Federation "Healthcare Development" (as amended on March 27, 2020) Accessed:

http://docs.cntd.ru/document/556183184.

12. On approval of the state program of the Russian Federation "Development of Education" (as amended on April 4, 2020) Accessed: http://docs.cntd.ru/document/556183093

13. K. E. Filushina, N. V. Gusakova, A. M. Gusakov, N. N. Minaev, and O. I. Dobrynina, J. Economy and Entrepr. 10-3, 423-426 (2016).

14. A.M. Nagimova, Housing conditions as a factor in the quality of life of the region's population (sociological analysis according to the research results), Bulletin of economics, law, sociology. 4, 187-191 (2010) [in Russian]. 